\title{
Reduction of AM-induced penalty in DPSK receivers by sum-square demodulation
}

\author{
Nielsen, T. N.; Gliese, Ulrik Bo; Stubkjær, Kristian
}

Published in:

I E E E Photonics Technology Letters

Link to article, DOI:

10.1109/68.122391

Publication date:

1992

Document Version

Publisher's PDF, also known as Version of record

Link back to DTU Orbit

Citation (APA):

Nielsen, T. N., Gliese, U. B., \& Stubkjær, K. (1992). Reduction of AM-induced penalty in DPSK receivers by sum-square demodulation. I E E E Photonics Technology Letters, 4(3), 275-277.

https://doi.org/10.1109/68.122391

\section{General rights}

Copyright and moral rights for the publications made accessible in the public portal are retained by the authors and/or other copyright owners and it is a condition of accessing publications that users recognise and abide by the legal requirements associated with these rights.

- Users may download and print one copy of any publication from the public portal for the purpose of private study or research.

- You may not further distribute the material or use it for any profit-making activity or commercial gain

- You may freely distribute the URL identifying the publication in the public portal

If you believe that this document breaches copyright please contact us providing details, and we will remove access to the work immediately and investigate your claim. 


\section{ACKNOWLEDGMENT}

The authors wish to thank the Managing Director of OTC for permission to publish this paper.

\section{REFERENCES}

[1] P. P. Smyth, R. Wyatt, A. fidler, P. Eardley, A. Sayles, and S. Craig-Ryan, " 152 photons per bit detection at $622 \mathrm{Mbit} / \mathrm{s}$ to 2.52 Gbit/s using an erbium fiber preamplifier," Electron. Lett., vol. 26, pp. 1604-1605, 1990.

[2] A. H. Gnauck and C. R. Giles, " $2.5 \mathrm{GBit} / \mathrm{s}$ and $10 \mathrm{GBit} / \mathrm{s}$ transmis- sion experiments using a 137 photons/bit erbium fiber preamplifier receiver," Proc. Europ. Conf. Opt. Comm., 1991, post deadline paper, pp. 60-63.

[3] B. Mikklesen, C. G. Joegensen, J. A. Vanden Berk, C. F. Pedersen, C. C. Larsen, T. Durhuus, and K. E. Stubkjaer, "High receiver sensitivity at $2.5 \mathrm{GBit} / \mathrm{s}$ obtained with a highly efficient low noise diode pumped erbium doped fibre amplifier," Opt. Ampl. Appl. Top. Meet., July 24-26, 1991, Snowmass Village, CO, pp. 192-195.

[4] P. M. Gabla, E. Leclerc, and C. Coeurjolly, "Practical implementation of a highly sensitive receiver using an erbium doped fibre preamplifier," in Proc. Europ. Conf. Opt. Comm., 1991, pp. $589-592$.

\title{
Reduction of AM-Induced Penalty in DPSK Receivers by Sum-Square Demodulation
}

\author{
T. N. Nielsen, U. Gliese, and K. E. Stubkjaer
}

\begin{abstract}
A DPSK demodulator which is insensitive to the amplitude modulation induced by semiconductor optical amplifier phase modulators is proposed. The demodulator consist of only two additional power dividers/combiners compared to a traditional DPSK demodulator. Analysis show that the receiver penalty caused by amplitude modulation can be reduced from 2-4 dB to zero. The demodulator is finally demonstrated in a $2.5 \mathrm{~Gb} / \mathrm{s}$ DPSK system experiment using an optical amplifier as phase modulator.
\end{abstract}

\section{INTRODUCTION}

CEMICONDUCTOR optical amplifiers (SOA's) can be Uused as phase modulators in optical communication systems [1]-[3]. Compared to traditional phase modulators (e.g., $\mathrm{LiNbO}_{3}$ phase modulators) the SOA has the advantages of gain and fairly low modulation power requirements. In addition, it lends itself readily to monolithic optoelectronic integration.

A problem of using SOA's as phase modulators is the amplitude modulation (AM) associated with the phase modulation (PM). The unwanted AM can be reduced by choosing an operating wavelength well above the peak gain wavelength [2], [4]. However, for operation at the peak gain wavelength, which is preferable due to the possibility for high net gain, the AM index for both bulk and MQW SOA's will be higher than $10 \%$.

Here we show that the receiver penalty induced by the AM

Manuscript received September 11, 1991; revised December 16, 1991. This work was supported in part by RACE Project 1027 .

The authors are with the Center for Broadband Telecommunications, Electromagnetics Institute, Technical University of Denmark, DK-2800 Lyngby, Denmark.

IEEE Log Number 9106427. can be reduced to zero in DPSK systems with an appropriate demodulator. The demodulation scheme is demonstrated in a $2.5 \mathrm{~Gb} / \mathrm{s}$ DPSK system experiment.

\section{Conventional DPSK Demodulation}

Conventional DPSK demodulation is performed by delay line discriminators as used in heterodyne coherent systems (c.f. Fig. 1). The bandpass filtered IF signal corresponding to one transmitted bit is given by

$$
i_{\mathrm{IF}}=I_{o}\left(1+m_{t}\right) \cdot \cos \left(\omega_{\mathrm{IF}} t+\phi_{t}\right)
$$

where $\omega_{\mathrm{IF}}$ is the intermediate frequency and $m_{t}$ describes the amplitude variation of the IF signal caused by the SOA. The PM is described by $\phi_{t}$ which takes the values $\pm \pi / 2$ in a DPSK system, and $I_{o}$ describes the optoelectric conversion factor.

The AM generated in SOA's is governed by the linewidth enhancement factor $\alpha$, giving the ratio between the PM and AM [5]; i.e., $m_{t}=\phi_{t} / \alpha$. The AM and PM generated by the SOA are both caused by modulation of the carrier density so $m_{t}$ and $\phi_{t}$ are correlated.

In a conventional DPSK demodulator, a mixer squares the IF signal with the IF signal delayed by one bitperiod $\tau$, and the PM-AM converted baseband signal is given by

$$
V_{b}=V_{o} \cdot\left(1+m_{t-\tau}\right)\left(1+m_{t}\right) \cdot \cos \left(\omega_{\mathrm{IF}} \tau+\Delta \phi\right)
$$

where subscript $\tau$ denotes the delayed bit and $V_{o}$ is a constant. $\Delta \phi=\left|\phi_{t}-\phi_{t-\tau}\right|$ is the phase difference between two succeeding bits and is either 0 (logic "space") or $\pi$ (logic "mark"). The term $\cos \left(\omega_{\mathrm{IF}} \tau\right)$ can take the value -1 or +1 depending on whether the logic "space" is repre-

$1041-1135 / 92 \$ 03.00$ (C) $1992 \mathrm{IEEE}$ 


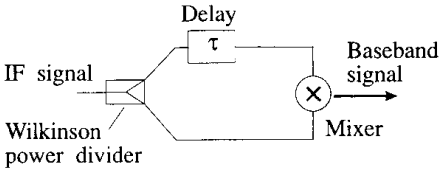

Negative
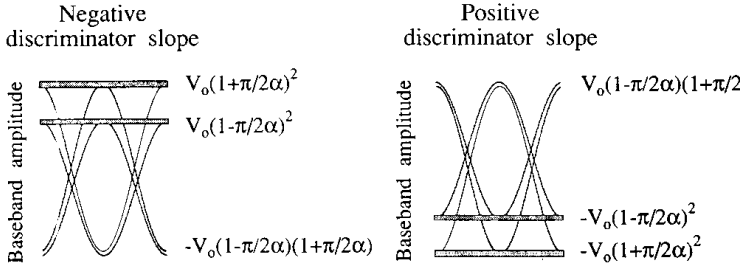

Fig. 1. Traditional DPSK demodulator and corresponding eye diagrams.

sented at the bottom or the top point of the discriminator curve, respectively.

The logic space, i.e., $\Delta \phi=0$, corresponds to the situation where $\phi_{t}=\phi_{t-\tau}= \pm \pi / 2$. The associated value for $m_{t}$ and $m_{t-\tau}$ is $\pm \pi / 2 / \alpha$ due to the correlation between PM and AM. The baseband amplitude corresponding to a "space", can therefore take the values $V_{o}(1 \pm \pi / 2 / \alpha)^{2}$, whereas the baseband amplitude for the logic "mark" only takes the value $V_{o}(1+\pi / 2 / \alpha)(1-\pi / 2 / \alpha)$. Because of the two "space" levels the resulting eye diagram will consist of two overlaid eye diagrams as shown in Fig. 1. Penalty is introduced due to the reduced baseband amplitude since the optimum decision level is placed between the "mark" and the lowest "space" level. From (2) it is furthermore seen that this baseband signal will appear independently of the chosen discriminator slope; i.e., $\cos \left(\omega_{\mathrm{IF}} \tau\right)$ equal to -1 or +1 .

\section{Sum-SQuare DPSK Demodulation}

In order to avoid the penalty caused by the AM, we propose a sum-square DPSK demodulator as shown in Fig. 2. Here the baseband signal is generated by adding the delayed IF signal to the IF signal itself and subsequently squaring the added signals in a mixer. The sum-square demodulator performs both a PM-AM conversion and an AM-AM conversion. The demodulated baseband signal is therefore given by

$$
\begin{aligned}
V_{b}=V_{o} \cdot & {\left[\frac{1}{2}\left(1+m_{t}\right)^{2}+\frac{1}{2}\left(1+m_{t-\tau}\right)^{2}\right.} \\
& \left.+\left(1+m_{t}\right)\left(1+m_{t-\tau}\right) \cos \left(\omega_{\mathrm{IF}} \tau+\Delta \phi\right)\right] .
\end{aligned}
$$

The baseband level for the logic "space" consist in this case of a contribution from the AM-AM conversion (two first terms) and a contribution from the PM-AM conversion (last term).

For the positive discriminator slope $\left(\cos \left(\omega_{\mathrm{IF}} \tau\right)=-1\right)$ the two contributions adds $180^{\circ}$ out of phase and the "space", level will only take the value 0 independent of the AM. So, for the positive discriminator slope only one eye diagram will appear, and the penalty induced by the amplitude variation is zero. It should be emphasized that this property is only valid because the phase and amplitude modulation generated by the SOA are correlated. For the negative discriminator slope (cos
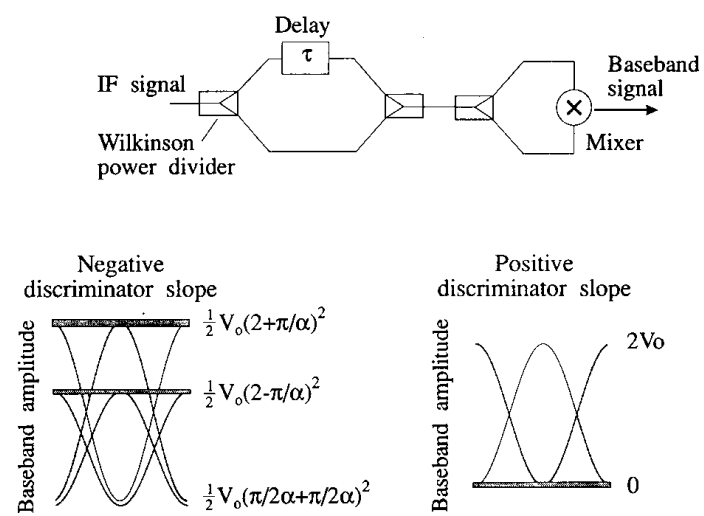

Fig. 2. Sum-square DPSK demodulator and corresponding eye diagrams.

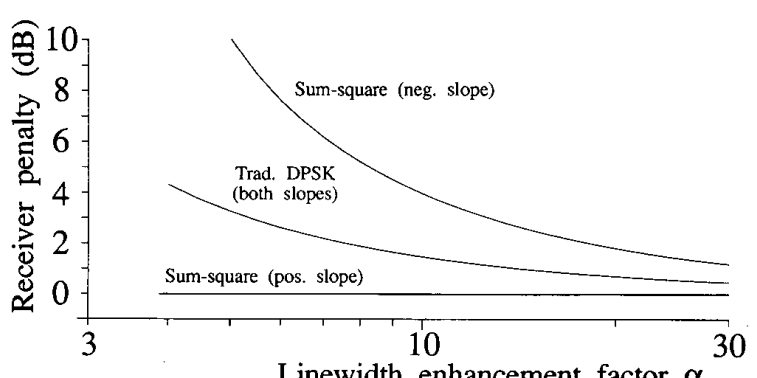

Fig. 3. Calculated AM-induced receiver penalty.

$\left.\left(\omega_{\mathrm{IF}} \tau\right)=+1\right)$ the two contributions add in phase and the AM-induced receiver penalty is even more severe than for the traditional DPSK demodulator.

The results are clarified in Fig. 3 where the calculated AM-induced receiver penalty in a DPSK system is shown as a function of the linewidth enhancement factor $\alpha$ for both the conventional DPSK demodulator and the sum-square demodulator. The calculations are based on the SNR and the AM-induced reduction of baseband amplitude. It should notice that equal baseband amplitudes will be generated by both schemes if no AM is present. It should be emphasized that zero receiver penalty is obtained independent of bit rate since the phase of the AM relative to the PM has no influence in this scheme.

It should also be noticed that demodulation on the positive discriminator slope can be assured without adding any system complexity. In a DPSK system the IF is restricted to a multiple of half the bit rate. Half of these IF values correspond to the positive discriminator slope and the other half to the negative. The only system constraint using the sum-square demodulation scheme is thus a reduction of the possible IF values by a factor of 2 .

\section{RESULTS}

The sum-square demodulation scheme is demonstrated in a $2.5 \mathrm{~Gb} / \mathrm{s}$ DPSK system experiment consisting of an optical delay line demodulator followed by a direct detection receiver [2]. This demodulation scheme is equivalent with the electrical sum-square scheme since the photodiode is a sum- 


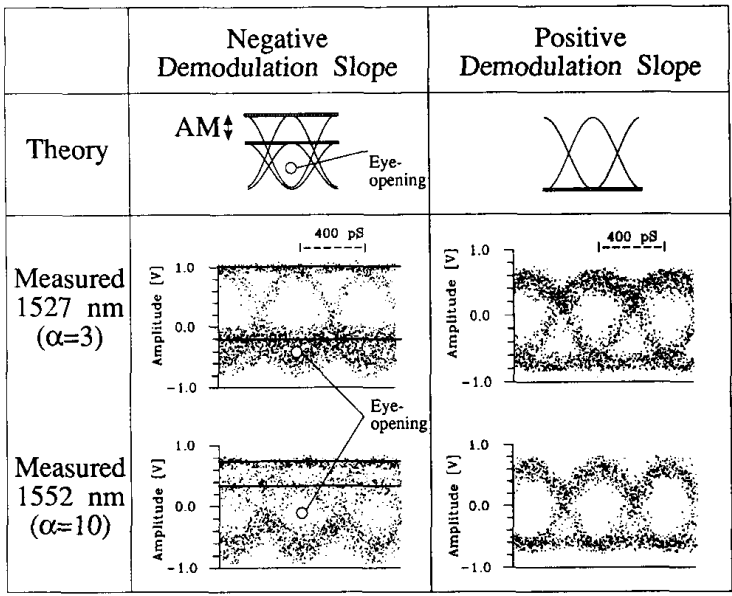

Fig. 4. Measured eye diagrams.

square detector. Light from a DFB laser is coupled into the SOA and the injection current is modulated with a $2.5 \mathrm{~Gb} / \mathrm{s}$ NRZ data signal. Furthermore, an equalizer is added in order to extend the bandwidth capability of the SOA [2], [3]. For the experiments, an optical input power level of $-7 \mathrm{dBm}$ is used and the fiber-to-fiber gain is $10 \mathrm{~dB}$, resulting in an optical output power of $+3 \mathrm{dBm}$.

Fig. 4 shows the measured eye diagrams obtained by demodulation on the two different slopes of the discriminator curve. Two transmitter lasers with different wavelengths are used to demonstrate the results for different AM-indexes. The AM-indexes due to the phase modulator are $15 \%(\alpha=10)$ and $50 \%(\alpha=3)$ for 1552 and $1527 \mathrm{~nm}$ wavelength, respectively.

For demodulation on the negative slope, a two-level eye diagram appears, whereas only one eye diagram appears for demodulation on the positive slope. It is furthermore seen that this result is independent of the amount of AM, and receiver penalty is consequently reduced to zero using the sum-square demodulation scheme.

\section{CONCLUSION}

We have proposed a sum-square DPSK demodulator which is insensitive to the amplitude modulation induced by SOA's used as phase modulators. Furthermore, a thorough analysis is presented for the eye diagrams that result from the conventional as well as the sum-square DPSK demodulator. Compared to the conventional DPSK demodulator, the sum-square demodulator only consists of two additional simple dividers/combiners, and the only system constraint to assure demodulation on the positive slope is a halving of the possible IF's.

In order to demonstrate the behavior of the demodulator, we have performed a $2.5 \mathrm{~Gb} / \mathrm{s}$ system experiment using an optical delay line demodulation that has the same property as the proposed electrical sum-square demodulation. The measurements show, in agreement with theory, that the proposed demodulation scheme is an attractive solution for reduction of the AM-induced receiver penalty. Semiconductor optical amplifiers operated at the peak gain wavelength can therefore, with great advantage, be used as phase modulators in DPSK systems in spite of the inevitable AM.

\section{ACKNOWLEDGMENT}

The authors would like to thank Dr. R. Pedersen for invaluable help on performing the system experiments and evaluating the measured eye diagrams. We also thank Dr. B. Fernier of Alcatel Alsthom Recherche for supplying the SOA.

\section{REFERENCES}

[1] G. Großkopf, R. Ludwig, R. Schnabel, and H. G. Weber, "Characteristics of semiconductor laser optical amplifier as phase modulator," Electron. Lett., vol. 25, pp. 1188-1189, Aug. 1989.

[2] T. N. Nielsen, U. Gliese, B. Mikkelsen, K. Stubkjaer, B. Fernier, P. Doussiere, and J.-L. Lafragette, "Characterization of high speed phase modulators based on semiconductor optical amplifiers," in Tech. Dig. 2nd Top. Meet. Opt. Amplifiers Appl., paper ThC2, pp. 130-133, July 1991, Snowmass Village, CO.

[3] T. N. Nielsen, U. Gliese, B. Mikkelsen, K. Stubkjaer, B. Fernier, B. Mersali, and A. Accard, " $2.5 \mathrm{~Gb} / \mathrm{s}$ DPSK system experiment using an optical amplifier as phase modulator," in Proc. 17th European Conf. Optical Commun. $/ 8$ th Internat. Conf. Integrated Opt Optical Commun., paper We.PS2.10, Sept. 1991, Paris, France.

[4] D. Reichenbach, C. E. Zah, N. Andreadakis, F. J. Favire, S. G Menocal, R. Vodhanal, A. Yi-Yan, and T. P. Lee, "Phase modulation characteristics of $1.5 \mu \mathrm{m}$ strained-layer multiple quantum well laser amplifiers," Electron. Lett., vol. 26, pp. 1858-1860, Oct. 1990.

[5] N. Storkfelt, B. Mikkelsen, D. S. Olesen, M. Yamaguchi, and K. E. Stubkjaer, "Measurement of carrier lifetime and linewidth enhancement factor for $1.5-\mu \mathrm{m}$ ridge-waveguide laser amplifier," IEEE Photon. Technol. Lett., vol. 3, July 1991. 